\title{
Occupational role stress is associated with higher cortisol reactivity to acute stress
}

Running title: Occupational role stress and stress reactivity

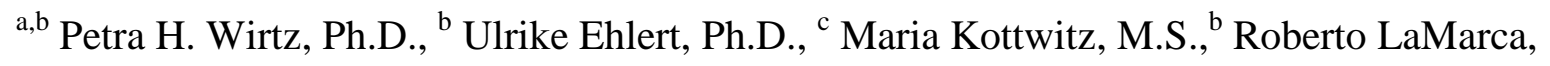
Ph.D. ${ }^{\mathrm{c}}$ \& $^{\mathrm{c}}$ Norbert K. Semmer, Ph.D.

\footnotetext{
${ }^{a}$ Biological and Health Psychology, Department of Psychology, University of Bern, Switzerland

${ }^{\mathrm{b}}$ Clinical Psychology and Psychotherapy, Psychological Institute, University of Zurich, Switzerland

${ }^{\mathrm{c}}$ Psychology of Work and Organizations, Department of Psychology, University of Bern, Switzerland
}

Address for correspondence and reprint requests:

Petra H. Wirtz, Ph.D.

Biological and Health Psychology

Department of Psychology

University of Bern

Alpeneggstrasse 22

3012 Bern, Switzerland

Tel.: +41 31631 5790, Fax: +41 31 4155, Email: petra.wirtz@psy.unibe.ch

Funding sources: This work was funded by research grants of the University of Zurich (Grant 56233203) and of the Swiss National Research Foundation (Grant PP00P1_128565/1) (both to PHW). 


\begin{abstract}
Objectives: We investigated whether occupational role stress is associated with differential levels of the stress hormone cortisol in response to acute psychosocial stress.

Methods: 43 medication-free non-smoking men aged between 22 and 65 years (mean \pm SEM: 44.5 \pm 2 ) underwent an acute standardized psychosocial stress task combining public speaking and mental arithmetic in front of an audience. We assessed occupational role stress in terms of role conflict and role ambiguity (combined into a measure of role uncertainty) as well as further work characteristics and psychological control variables including time pressure, overcommitment, perfectionism, and stress appraisal. Moreover, we repeatedly measured salivary cortisol and blood pressure levels before and after stress exposure, and several times up to 60 min thereafter.
\end{abstract}

Results: Higher role uncertainty was associated with a more pronounced cortisol stress reactivity $(\mathrm{p}=.016)$, even when controlling for the full set of potential confounders $(\mathrm{p}<.001)$. Blood pressure stress reactivity was not associated with role uncertainty.

Conclusions: Our findings suggest that occupational role stress in terms of role uncertainty acts as a background stressor that is associated with increased HPA-axis reactivity to acute stress. This finding may represent a potential mechanism regarding how occupational role stress may precipitate adverse health outcomes.

Key words: work stress, role stress, uncertainty, stress reactivity, cortisol 
Role stressors are an important source of stress at work; they seem to be widely experienced in the workplace, and at least a sizable minority of workers can be expected to experience role stress on a daily basis (Beehr \& Glazer, 2005; Kahn, Wolfe, Quinn, Snoek, \& Rosenthal, 1964). As introduced by Kahn and colleagues in 1964, role stress refers (a) to role conflict, with contradictory expectations from different people, and (b) role ambiguity, with unclear expectations as core elements (cf. Rizzo, House, \& Lirtzman, 1970). Later, role overload, which originally was part of role conflict, was separated as a construct in its own right, with a high workload in relation to resources available as its core element. All three constructs have been shown to relate to well-being (see the meta-analysis by Örtqvist \& Wincent, 2006); however, role overload differs from role conflict and role ambiguity in that overload contains a challenge aspect (LePine, LePine, \& Saul, 2007; Widmer, Semmer, Kalin, Jacobshagen, \& Meier, 2012); this is not true for role conflict and role ambiguity, which represent hindrance stressors (LePine, Podsakoff, \& LePine, 2005; Webster, Beehr, \& Love, 2011). Both role conflict and role ambiguity imply an uncertainty about which action is appropriate; we focus on this common element of the two, referring to "role uncertainty" as representing the common element of these two stressors (cf. Garst, Frese, \& Molenaar, 2000; O'Driscoll \& Beehr, 1994; Widmer, Semmer, Kalin, et al., 2012).

Role stressors have repeatedly been shown to be associated with a variety of negative outcomes (Beehr \& Glazer, 2005). Among others, these include higher emotional exhaustion and depersonalization, both key features of vital exhaustion, which is an independent risk factor for coronary heart disease (Appels, 2004; Örtqvist \& Wincent, 2006); they also include tension/anxiety (Jackson \& Schuler, 1985; Kemery, Bedeian, Mossholder, \& Touliatos, 1985; Örtqvist \& Wincent, 2006; Price \& Hooijberg, 1992; Schaubroeck, Cotton, \& Jennings, 1989; Spector, Dwyer, \& Jex, 1988), depression (Beehr, 1976; Caplan \& Jones, 1975; Ganster, Fusilier, \& Mayes, 1986; Price \& Hooijberg, 1992), as well as somatic complaints (Ganster \& Schaubroeck, 1991; Kemery, Mossholder, \& Bedeian, 1987) and subjectively perceived 
physical health (Frone, Russell, \& Cooper, 1995), although some of these associations are qualified by interactions with other variables (e.g., job involvement in Frone, Russell, \& Cooper, 1995). Furthermore, self-esteem (Jackson \& Schuler, 1985) and organization-based self-esteem (Widmer, Semmer, Kälin, Jacobshagen, \& Meier, 2012) have been found to be associated with role stress. It has to be noted, however, that most of these studies are crosssectional, although the few longitudinal studies also found role stress to predict anxiety/tension (Caplan \& Jones, 1975) and anxiety as well as depression (Price \& Hooijberg, 1992). Furthermore, most of the studies are based on self-report of both stressors and strain and thus may carry the problem of common method bias. However, there are a few studies that do show associations between role ambiguity and/or role conflict with heart disease (cf. Cooper \& Marshall, 1976; Danna \& Griffin, 1999; House, 1974), and Howard, Cunningham, \& Rechnitzer (1986) showed that increases in role ambiguity were associated with changes in blood pressure and triglycerides (Howard, Cunningham, \& Rechnitzer, 1986). Nevertheless, more studies that allow distinguishing between cause and effect with more confidence and / or apply a multimethod approach are needed to overcome such shortcomings.

Role stressors are among the most widely studied occupational stressors (Beehr \& Glazer, 2005), p. 11). Role overload is especially prominent, as many models on stress at work refer to demands, workload, effort, or similar concepts (e.g., Siegrist, 1996; Theorell \& Karasek, 1996). By contrast, research on associations between role uncertainty (i.e., role conflict and role ambiguity) and strain seems to have waned. In contrast to other models, such as the Job Demands Control model (R. A. Karasek, 1979), the Effort-Reward Imbalance Model (Siegrist, 1996), and, more recently, justice models (Greenberg, 2010), the role stress model is not specifically mentioned in recent reviews and meta analyses concerning the association of work stress and health, most notably cardiovascular disease (CVD; e.g., Backe, Seidler, Latza, Rossnagel, \& Schumann, 2012; Kivimaki et al., 2012; Kivimaki et al., 2006); furthermore, almost half (46\%) of the references in the most recent comprehensive review on 
role stress (Beehr \& Glazer, 2005) refer to publications of 1990 and earlier. This state of affairs seems unfortunate; arguably, uncertainty reflects a core aspect of the stress experience, as argued by Mason already in 1968, and reflected in Beehr's uncertainty theory of occupational stress (Beehr, 1998; Beehr \& Bhagat, 1985). Furthermore, as explicated below, role uncertainty may be of special importance for processes involved in stress-related development of cardiovascular disease.

\section{Work Stress and Cardiovascular Disease Development}

Accumulating prospective evidence suggests that stressful conditions at work are associated with adverse health outcomes, particularly with regard to cardiovascular health (Backe, et al., 2012; Kivimaki, et al., 2012; Kivimaki, et al., 2006; Steptoe \& Kivimaki, 2012). As mentioned above, role uncertainty is not specifically mentioned in these reviews; for reasons discussed below, this is unfortunate, as role uncertainty possessed qualities that make it a likely predictor of cardiovascular dysregulation. There are different pathways through which chronic work stress could contribute to the risk of CVD; one of them relates to inducing changes in the reaction to acute stressful situations (McEwen, 1998a; Steptoe \& Kivimaki, 2012).

According to the stress-reactivity hypothesis, the study of short-term physiological responses to controlled challenges such as an acute psychosocial stress task serves as a window into the complex psychophysiological processes involved in the development of cardiovascular disease (Linden, Gerin, \& Davidson, 2003; Lovallo \& Gerin, 2003). In particular, large-magnitude physiological reactions to acute stressors have been shown to predict poor cardiovascular health outcomes (Brotman, Golden, \& Wittstein, 2007; Chida \& Steptoe, 2010).

Physiological responsivity depends on many factors. Arguably, repeated or prolonged responses required by frequent or persistent stressors might not only induce changes in tonic 
levels of parameters of the hypothalamus-pituitary-adrenal (HPA) axis and the sympathetic nervous system (SNS) (cf. Melamed et al., 1999) but also change the regulatory system itself. Such an argument has been made especially forcefully by allostatic load theory (e.g., McEwen, 1998b), and chronic stressors that alter physiological responsivity have been termed background stressors by Gump and Matthews (1999), indicating that the acute response occurs against a background of more persistent conditions, which may influence the acute response.

An early study by Steptoe and colleagues (Steptoe, Fieldman, Evans, \& Perry, 1993) assessed job strain according to the demand-control model (R. Karasek \& Theorell, 1990) and found higher cardiovascular reactivity to acute stress. However, long-lasting chronic stress exposure has also been hypothesized to exhaust physiological stress reactivity capacity, which in turn may result in lowered physiological stress reactivity (Appels, 1997; McEwen, 1998a; Wirtz, Siegrist, Rimmele, \& Ehlert, 2008). Indeed, both elevated as well as reduced responsivity to acute stress have been found for both SNS and HPA parameters (Chida \& Hamer, 2008). Thus, chronic stress at work may be associated with both heightened and reduced physiological reactivity to acute stress.

A model that may allow at least in part to integrate some of these contradictory findings is Dienstbier’s model of toughness (Dienstbier, 1989). Dienstbier distinguishes between acute reactivity and recovery of SNS and HPA axis measures, making different predictions about how each system will respond to stress with a focus on intermittent events that toughen these response systems. According to Dienstbier a fit or toughened organism shows low base rates of both SNS and HPA parameters, and an optimal response to acute stress in terms of strong and responsive reactivity of SNS, but not HPA, parameters, together with fast recovery of both systems. Conversely, a less fit organism shows elevated base rates in both system, but displays a strong HPA but weak SNS response, with slow recovery in both systems. Schaubroeck and Ganster (Schaubroeck \& Ganster, 1993) specify the untoughening 
process in terms of chronic demands with little opportunity for adaptation or control, such as chronic work stress exposure. In line with other findings including our own (Chida \& Hamer, 2008; Hamer et al., 2006; Siegrist, Klein, \& Voigt, 1997; Wirtz, et al., 2008) Schaubroeck and Ganster found evidence for lower responsivity (and in part prolonged recovery) of SNS parameters including blood pressure (Schaubroeck \& Ganster, 1993) following standardized challenge in participants with high, as compared to low, chronic occupational stress. Similarly, the meta-analysis by Chida and Hamer (2008) found at least tentative evidence for reduced reactivity of parameters reflecting SNS, such as catecholamines and blood pressure.

With regard to the acute reactivity and recovery of HPA axis measures following acute stress, there are too few studies to draw firm conclusions; thus, Chida \& Hamer (Chida \& Hamer, 2008) could not locate enough empirical studies to run a meta-analysis concerning the effect of job-related background stressors on acute HPA-reactivity. Further research therefore is needed.

In sum, the toughness model predicts high cortisol but low cardiovascular responsivity to acute stress for people exposed to chronic stress, as well as slow recovery for both systems. The studies cited above led us to conclude that there is some support for the low cardiovascular reactivity, whereas support for the high cortisol reactivity hypothesis is mixed. One reason for the mixed findings may refer to the nature of the stressors. According to Dickerson and Kemeny’s (2004) meta-analysis (Dickerson \& Kemeny, 2004), stressors are most likely to elicit increased cortisol responses if they involve a social-evaluative threat and/or if they are uncontrollable. These characteristics apply both to our acute stressor and to the background stressor of role uncertainty. Clearly, the Trier Social Stress Test (TSST) that we used (see below) involves a danger of losing face and appearing incompetent. Not surprisingly, therefore, the TSST is mentioned by Dickerson and Kemeny (2004) as a prototypical standardized situation that should evoke strong cortisol responses. The background stressor, role uncertainty, refers to unclear or contradictory expectations of 
superiors and thus represent a condition that the person cannot easily control and that involves the danger of social disapproval. Thus, employees who do not have a clear idea about what exactly is expected from them run the risk of being reprimanded for doing the "wrong” thing; asking for clarification may imply the risk of appearing incompetent (i.e., failing to comprehend what one should do) or of criticizing the superior for not being clear. Being confronted with conflicting expectations also creates uncertainty, as it is difficult to decide whom to follow; furthermore, whatever one decides may provoke negative reactions from the one who's expectations are not met, and therefore a negative social evaluation is quite likely. Thus, role uncertainty creates a condition that seems to resemble closely the characteristics of situations leading to high, as opposed to low, HPA reactivity, that is, involving a socialevaluative threat and low controllability. By containing these elements, role uncertainty represents a background stressor that "matches" some of the crucial characteristics of the TSST. Such a match may represent an optimal condition for eliciting high, as opposed to low, HPA responses (cf. the call for a closer matching by Dickerson and Kemeny, 2004, p. 382). To the best of our knowledge, role uncertainty, representing the combination of role conflict and role ambiguity, has not yet tested with regard to physiological stress reactivity.

Therefore, based on the toughness model and on the specific characteristics of the stressors we investigated, we expect HPA reactivity to an acute social stressor to be stronger for participants higher in role uncertainty. Using cortisol as an indicator of the HPA axis, we propose:

Hypothesis 1: Cortisol responsivity to the Trier Social Stress Test will be stronger for participants high in role uncertainty, compared to participants low in role uncertainty.

For SNS-reactivity, expectations are different: Based on the toughness model, and on the available empirical evidence we expect low SNS responsivity for people with high background stressors. Using blood pressure as an SNS-indicator, we propose: 
Hypothesis 2: Blood pressure responsivity to the Trier Social Stress Test will be weaker for participants high in role uncertainty, compared to participants low in role uncertainty.

\section{METHODS}

\section{Study participants}

Recruitment was carried out by members of the research team who accompanied the mobile blood donation units of the Swiss Red Cross of the Canton of Zurich. We recruited non-smoking middle-aged men who were healthy as confirmed by a telephone interview using an extensive health questionnaire (Wirtz et al., 2003). Exclusion criteria, obtained by subjects' self-report, were: clinical psychosomatic and psychiatric diseases, regular strenuous exercise, alcohol and illicit drug abuse; any heart disease, varicosis or thrombotic diseases, elevated blood sugar and diabetes, elevated cholesterol, liver and renal diseases, chronic obstructive pulmonary disease, allergies and atopic diathesis, rheumatic diseases, and current infectious diseases. In addition, participants were included only if they reported taking no medication, either regularly or occasionally. If the personal or medication history was not conclusive, the subjects’ primary care physician was contacted for verification. The study sample comprised 43 men (mean age \pm SEM: $44.5 \pm 2.0$ years, mean body mass index \pm SEM: $25.7 \pm$.4) who completed the measure of role uncertainty (see below). Our participants reported a great variety of different jobs including technicians, engineers, teachers, or craftsmen, and most (61.4\%) worked for a private employer. All subjects provided written informed consent. The Ethics Committee of the Canton of Zurich, Switzerland, formally approved the research protocol. 


\section{Study protocol}

All subjects reported to the laboratory on a single study day. Subjects were tested between 2:00 pm and 4:00 pm. They had abstained from physical exercise, alcohol, and caffeinated beverages since the previous evening. They were exposed to the Trier Social Stress Test (TSST), which combines a 5-min preparation phase followed by a 5-min mock job-interview, and 5-min mental arithmetic in front of a jury that displayed a stern attitude (Kirschbaum, Pirke, \& Hellhammer, 1993). The TSST has been used frequently, and it reliably induces increases in biochemical parameters, most notably cortisol (Dickerson \& Kemeny, 2004; Kudielka, Hellhammer, \& Kirschbaum, 2007). During the 45 min before introduction to the TSST and another 60 min after task completion, subjects remained seated in a quiet room. Questionnaires were administered during the resting period prior to TSST.

For determination of salivary cortisol levels, saliva samples were taken immediately before as well as every ten minutes, at $0,10,20,30,40,50$ and 60 minutes after completion of the TSST. Blood pressure (BP) was measured by sphygmomanometry (Omron 773, Omron Healthcare Europe B.V. Hoofddorp, The Netherlands), and BP stress reactivity was assessed by recordings immediately before and after stress, as well as 10 and 20 min thereafter. Mean arterial blood pressure (MAP) was calculated by the formula $(2 / 3 *$ mean diastolic BP $)+(1 / 3$ mean systolic BP) (Schmidt \& Thews, 1987) from measurements immediately before and 50 min after the TSST.

\section{Measurements and Data analysis}

\section{Role uncertainty}

Role uncertainty was measured by 3 Likert-scaled items of the scale "uncertainty” from the “Instrument for Stress-oriented Task Analysis” (ISTA) (Semmer, Zapf, \& Dunckel, 1995), a well-established instrument in German-speaking countries (cf. Sonnentag, Binnewies, \& Mojza, 2010). The uncertainty scale assesses role ambiguity and role conflict: (1) "How often 
to you get unclear instructions?”; (2) “How often do you get conflicting instructions from different supervisors?”; (3) “From how many people do you receive instructions on a regular basis?”). Items had a 5-point Likert format, ranging from 1 (very seldom/never) to 5 (very often); scores range from 1 to 5 , with higher scores reflecting higher uncertainty. Cronbach’s alpha was .67.

\section{Psychological control variables}

The current project is part of a larger series of studies investigating psychological determinants of physiological stress reactivity (Gaab, Rohleder, Nater, \& Ehlert, 2005; Wirtz, Ehlert, et al., 2006; Wirtz, Elsenbruch, et al., 2007; Wirtz, Kanel, et al., 2007; Wirtz, Redwine, Ehlert, \& von Kanel, 2009; Wirtz, et al., 2008). We therefore assessed psychological control variables (i.e. overcommitment, perfectionism, and cognitive stress appraisal) that we previously found to independently relate to stress reactivity measures of the HPA axis and the sympathetic nervous systems (Gaab, et al., 2005; Wirtz, Elsenbruch, et al., 2007; Wirtz, et al., 2008)_ENREF 6 ENREF 7. We additionally controlled for time pressure at work; time pressure reflects the workload construct, which is both a typical work-related stressor and part of the role stress concept (Beehr \& Glazer, 2005), and thus associated with work-related uncertainty scores (R. Karasek \& Theorell, 1990; Semmer, et al., 1995). As we argued that role uncertainty is specifically pertinent for inducing high (rather than low) HPA responsivity, we wanted to control for time pressure at work to make sure that potential effects are not simply due to stress at work in general but specifically to role uncertainty.

Overcommitment. Overcommitment was assessed by a scale composed of 6 Likertscaled items where respondents indicated to what extent they agreed or disagreed with the given statements on a four-point rating scale, from 1 (completely disagree) to 4 (completely agree). A sample item is "People close to me say I sacrifice too much for my job". The scale exhibited high internal consistency in previous analyses and had an acceptable scalability 
(Siegrist et al., 2004) and an appropriate goodness of fit (Hanson, Schaufeli, Vrijkotte, Plomp, \& Godaert, 2000; Joksimovic, Starke, v d Knesebeck, \& Siegrist, 2002; Roedel, Siegrist, Hessel, \& Braehler, 2004). In our study, Cronbach’s alpha was .68.

Perfectionism. We assessed perfectionism by measuring “concern over mistakes and doubts” (CMD, 13 Items on 5-point rating scales for each item, ranging from 1 (strongly disagree) to 5 (strongly agree), minimum score $=13$, maximum score $=65$ ) of the German Version of the Frost Multidimensional Perfectionism Scale (MPS-d, Frost, Marten, Lahart, \& Rosenblate, 1990; Stöber, 1998; Wirtz, Elsenbruch, et al., 2007). A sample item is "If 1 do not do as well as other people, it means I am an inferior human being“. Cronbach’s alpha was .76.

Cognitive stress appraisal. To address anticipatory cognitive appraisal processes relevant for the TSST, we assessed the total stress appraisal resulting from primary )i.e., the judgment about the significance of an event as stressful, positive, controllable, challenging, or irrelevant) and secondary appraisal processes (i.e., the assessment of available coping resources and options when faced with a stressor). We used a 16-item questionnaire for Primary and Secondary Appraisal (PASA) (Gaab, et al., 2005), which is based on the theoretical constructs proposed by Lazarus and Folkmann (Lazarus \& Folkman, 1984)_ENREF 40.

Subjects had to evaluate the extent to which the particular statement applied to themselves on a 6-point scale ranging from 1 (strongly disagree) to 6 (strongly agree). A sample item is "I do not feel threatened by the situation”. Cronbach’s alpha was .76.

Work-related time pressure. Time pressure was measured by self-report, using a 4item subscale of the Instrument for Stress Oriented Task Analysis (ISTA) (Semmer, et al., 1995). Items included questions like "How often does it happen that you go home late because of too much work?”. Items have a 5-point Likert format reflecting frequency (ranging from “very seldom/never” to “very often/always”). Cronbach’s alpha was .87. 


\section{Cortisol analyses}

For measurement of cortisol, saliva was collected using Salivette collection devices (Sarstedt, Rommelsdorf, Germany), which were stored at $-20^{\circ} \mathrm{C}$ until biochemical analysis. Cortisol concentrations were determined in the Psychoneuroendocrinological Laboratory of the University of Dresden, Germany, with a commercially available competitive chemiluminiscence immunoassay with high sensitivity of $0.16 \mathrm{ng} / \mathrm{ml}$ (LIA, IBL Hamburg, Germany). Intra- and inter-assay variability was less than $10 \%$.

\section{Statistical analyses}

Data were analyzed using SPSS (version 19.0) statistical software package (SPSS Inc., Chicago IL, USA). All tests were two-tailed with level of significance set at $p \leq .05$ and level of borderline significance set at $\mathrm{p} \leq 10$. Prior to statistical analyses all data were tested for normality using the Kolmogorov-Smirnov test. Missing data were list-wise excluded. As an apriori fixed set of physiological control variables, we controlled for the cardiovascular risk factors age, body mass index (BMI), and mean arterial blood pressure (MAP) in all analyses. Psychological control variables included person-related parameters that have been shown to relate to altered cortisol stress reactivity, i.e. overcommitment (Wirtz, et al., 2008) and perfectionism (Wirtz, Elsenbruch, et al., 2007), as well as cognitive stress appraisal (Gaab, et al., 2005). Furthermore, we additionally controlled for perceived time pressure at work to rule out a confounding influence of this typical work-related stressor on potential associations between work-related uncertainty and physiological stress reactivity.

We calculated Pearson's product-moment correlations to test for associations between job-related uncertainty and cortisol at rest, as well as between uncertainty and the psychological measures overcommitment, time pressure, perfectionism, and stress appraisal. 
Following previous methods (Wirtz, et al., 2009; Wirtz et al., 2010; Wirtz, von Kanel, et al., 2006) we assessed associations between uncertainty and the cortisol / blood pressure stress response by calculating general linear models with repeated measures of cortisol / blood pressure) as dependent variable and role uncertainty as continuous independent variable while controlling for age, BMI, and MAP as covariates in the main analysis. In secondary analyses, we additionally controlled for the set of potential psychological confounders as described before (i.e. overcommitment, perfectionism, stress appraisal, and time pressure at work). We applied Huynh-Feldt corrections for repeated measures.

To graphically illustrate our findings, we categorized the study group into quartiles based on their role uncertainty scores with lowest uncertainty in quartile 1 and highest uncertainty in quartile 4; results are displayed in Figure 1. Note that our statistical analyses are based on uncertainty as a continuous variable; we calculated quartiles for the purpose of illustration only.

Significant ANCOVA results were further analysed by applying post -hoc tests to ascertain whether the observed total stress reactivity effect related to altered immediate stress reactivity and/or to altered recovery. As a measure of immediate stress reactivity we calculated a maximum stress change score by computing the area under the curve with respect to increase (AUCi, Pruessner, Kirschbaum, Meinlschmid, \& Hellhammer, 2003) from the baseline of the significant physiological parameter to its stress reactivity peak. As a measure of stress recovery we calculated the AUCi from the stress reactivity peak of the respective physiological parameter to the last measured level (AUCi recovery). Associations between uncertainty and AUCis were estimated in subsequent multiple linear regression analyses with the respective AUCi as dependent variable and role uncertainty scores as well as the above described confounders as independent variables. 


\section{RESULTS}

\section{Group characteristics and correlations}

Table 1 depicts sociodemographic, medical, and psychological characteristics of the study group. Role uncertainty significantly related to time pressure $(r=.43, p=.005)$ but not to any of the other psychological measures (overcommitment: $r=-.13 ; p=.43$; stress appraisal: $r=-.22 ; p=.16$; perfectionism: $r=.23 ; p=.15$ ). Notably, except for two participants who reported to work 88 and 84 hours per week, weekly working hours were between 16 and 60 . Table 2 depicts the correlation matrix of the measured variables.

\section{Associations between work-related uncertainty and physiological stress reactivity}

\section{At rest}

At rest, role uncertainty did not relate to cortisol or blood pressure (see Table 2). Additional controlling for the full set of confounders did not significantly change these findings ( $p$ ’s > .33).

\section{Stress reactivity}

Stress induction by TSST induced significant increases in cortisol (main effect of stress: $F(2.0 / 80.8)=47.5, p<.001$, partial eta $\left.{ }^{2}=.54, f=1.09\right)$ and blood pressure (SBP: $F(2.5 / 102.6)=14.9, p=.001$, partial eta ${ }^{2}=.27, f=.60 ;$ DBP: $F(2.9 / 114)=18.7, p=.001$, partial eta $\left.{ }^{2}=.33, f=.69\right)$.

Cortisol. As depicted in Table 3, general linear models with repeated cortisol measures and role uncertainty as continuous independent variable, and age, BMI and MAP as covariates, revealed that higher role uncertainty scores were associated with higher cortisol stress reactivity (interaction uncertainty-by-TSST: $F(2.5 / 89.4)=3.94, p=.016$, 
partial eta $\left.{ }^{2}=.10, f=.33\right)$. Further controlling for the second set of confounders (overcommitment, stress appraisal, perfectionism; time pressure) did not change the results; they actually got stronger (interaction uncertainty-by-TSST: $F(3.9 / 105.7)=6.57, p<.001$,

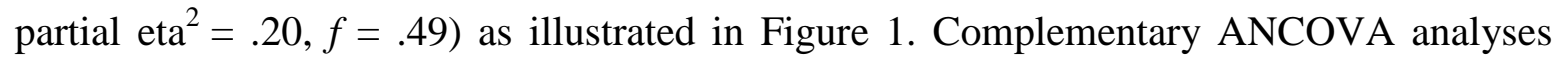
revealed that additional controlling for baseline cortisol provided similar results for the association between role uncertainty and the remaining cortisol measurements (interaction uncertainty-by-TSST: $F(2.7 / 105.7)=6.96, p<.001$, partial eta $\left.{ }^{2}=.21, f=.52\right)$.

To distinguish between initial stress responsivity and recovery, we post-hoc calculated the AUCi of the maximum stress change score (AUCi stress change) from baseline to $20 \mathrm{~min}$ after stress for cortisol. As a measure of stress recovery we calculated the AUCi from 20 min after stress to 60 min after stress. Multiple linear regression analyses revealed that, controlling for age, BMI, and MAP, role uncertainty related both to a higher cortisol maximum stress change (AUCi stress change: $\beta=.45, p=.025, \Delta \mathrm{R}^{2}=.12$ ) as well as to slower recovery, as indicated by higher AUCi recovery scores (AUCi recovery: $\beta=.44, p=.028, \Delta \mathrm{R}^{2}=.12$ ). Additionally controlling for overcommitment, stress appraisal, perfectionism, and time pressure did not weaken, but rather improved, associations between uncertainty and maximum cortisol stress change (AUCi stress change: $\beta=.57, p=.005$, $\Delta \mathrm{R}^{2}=.12$ ), whereas associations with altered recovery became of borderline significance (AUCi recovery: $\beta=.36, p=.09, \Delta \mathrm{R}^{2}=.05$ ).

Blood pressure. Controlling for age, BMI, and MAP, role uncertainty did not significantly relate to stress reactivity of systolic $\left(F(2.7 / 99.7)=1.73, p=.17\right.$, eta $^{2}=.05, f$ $=.21$ ) or diastolic blood pressure $F(3.0 / 105.0)=.27, p=.85$; eta $^{2}=.008, f=.09$ ). Additionally controlling for psychological confounders did not significantly change these results (SBP: $p=.53$; DBP: $p=.66)$.

\section{DISCUSSION}


Our study investigated for the first time whether role uncertainty at work as a background stressor related to altered physiological reactivity to acute psychosocial stress in working men. The main finding of our study was that higher role uncertainty was associated with higher cortisol stress reactivity even when controlling for a broad set of potential confounders including cardiovascular risk factors and potentially confounding psychological constructs ${ }^{1}$. These results are in line with Hypothesis 1 . In contrast, blood pressure stress reactivity did not relate to role uncertainty, disconfirming Hypothesis 2. Moreover, as indicated by post-hoc analyses of the areas under the respective increase curves, the overall heightened cortisol reactivity with increasing role uncertainty comprised higher immediate stress reactivity as well as slower recovery. Resting levels of both cortisol and blood pressure were unrelated to reactivity measures.

These results confirm the general finding that physiological reactivity to acute stress is not independent of chronic conditions in terms of background stressors (Gump \& Matthews, 1999); they add credibility to the suggestion that one way through which chronic stress may lead to cardiovascular disease is by inducing a dysregulation in reactions to acute stressors. Given that higher cortisol stress reactivity has been shown to predict coronary artery calcification as an indicator of atherosclerosis, our findings might point to elevated coronary heart disease risk with increasing role uncertainty (Hamer, Endrighi, Venuraju, Lahiri, \& Steptoe, 2012; Hamer, O'Donnell, Lahiri, \& Steptoe, 2010; Seldenrijk, Hamer, Lahiri, Penninx, \& Steptoe, 2012). However, future studies are needed to provide empirical support for such reasoning. At the same time, in line with the toughening model our findings suggest that background stressors may not be associated with altered physiological stress reactivity in the same way with regard to the HPA-axis and SNS parameters. Rather, the positive association with cortisol stress reactivity indicates a distinct

\footnotetext{
${ }^{1}$ Following the suggestion of a reviewer, we additionally controlled for trait anxiety; trait anxiety was not related to cortisol reactivity $(p=.56)$ nor did it significantly change the association between uncertainty and repeated cortisol: $F=6.2$, $\mathrm{p}<.001$. Detailed results concerning these analyses can be obtained from the first author.
} 
association with heightened reactivity of the HPA axis when confronted with an acute psychosocial stressor. In contrast, the SNS in terms of blood pressure remained unaffected, both at baseline and in response to stress.

How do these results relate to the toughening concept? They provide partial support in that cortisol reactivity is higher among people with comparatively high role uncertainty, which is what the toughening model would predict. They also provide partial support in that blood pressure does not react the same way; however, the toughening concept would have predicted a hypo-response, that is, a weaker blood pressure response in participants comparatively high, as compared to low, in role uncertainty. We did not obtain this hyporeactivity, disconfirming this aspect of the toughening model, and thus our Hypothesis 2, which was based on that model.

Although we were not specifically concerned with recovery, we did find slower recovery for cortisol, which is in line with Ganster and Schaubroeck (1993) as well as with earlier research by Frankenhaeuser and Johannson (1986). This finding is especially important in light of the increasing awareness that recovery might play a crucial role in the development of health impairments due to stress (Geurts \& Sonnentag, 2006).

There are several ways to explain the results concerning blood pressure, all of which must, however, remain speculative. A methodological explanation would simply refer to our small sample and the corresponding lack of power and greater sampling error. A more substantive explanation would suggest that the HPA and SNS systems differ in their ability to habituate or learn. Some support for this explanation comes from findings suggesting that the HPA axis is more sensitive to learning effects (Schommer, Hellhammer, \& Kirschbaum, 2003). One may speculate that the background stress due to role uncertainty may interact with the stress-inducing elements of the TSST-situation in potentiating HPA axis reactivity; thereby, uncertainty may create a state of learned enhanced sensitization of HPA axis activation. Consequently, HPA axis reactivity following stress would be enhanced in 
persons with higher uncertainty scores. Such learning effects are not found for the SNS, as shown by findings that it does not habituate to repeated stress exposition (Schommer, et al., 2003), at least as long as the system is not too exhausted to react normally (Wirtz, et al., 2008). Thus, the SNS might remain unaffected by potential learning effects due to relatively moderate uncertainty background stress; this may prevent the SNS from learned sensitization effects when stimulated.

Regardless of whether our attempts at explaining these results can be held up, however, we hasten to add that they are unlikely to hold for HPA and SNS reactivity regardless of the stressors involved and the length of time people have been exposed to these stressors. For both systems, there is so much empirical support for both hyper- and hypo-reactivity (Chida \& Hamer, 2008; Hamer, et al., 2006; Siegrist, et al., 1997; Wirtz, et al., 2008) that it seems inevitable to conclude that moderators must be present. One such moderator is time, as many authors agree that both systems are likely to show hyporeactivity when stress has accumulated to such an extent that the systems get exhausted (Siegrist, et al., 1997). As we have no information about the length of time our participants had been exposed to role uncertainty, we cannot deal with time in the context of our study. However, one can assume that the two-stage model would require a long-term exposure to stress that exceeds a minimal threshold. Given the rather low values of role uncertainty, it seems unlikely that our participants would have reached this stage, which would make hyper-, rather than hypo-reactivity, more likely in our study. Our results therefore indicate a response that is somewhat compromised, but not to the extent that the system has become unable to respond.

Another moderator concerns the nature of the stressors involved. As outlined in the introduction, role uncertainty is especially pertinent with regard to the HPA axis. Mason has emphasized already in 1968 that the HPA axis is activated in situations that are novel, ambiguous, and unpredictable, that include ego-involvement, or anticipation of negative 
consequences. Dickerson and Kemeny (2004) found that stressors are most likely to elicit increased cortisol responses if they involve a social-evaluative threat and/or if they are uncontrollable. These characteristics apply both to our acute stressor and to the background stressor of role uncertainty. Thus, we would not claim that our results are generalizable to other stressors with different qualities; this conclusion is strengthened by our findings regarding time pressure. Controlling for time pressure, which is correlated with role uncertainty (see Table 1) does not weaken our results, as one would expect if time pressure had a similar association with HPA reactivity as role uncertainty does; to the contrary, controlling for time pressure actually strengthens our results, suggesting that time pressure contains variance that is associated with HPA reactivity in the opposite way; partialling out time pressures removes that part of the variance from the role uncertainty measure, making the specific effect of role uncertainty even clearer. These results suggest that role uncertainty has specific qualities as a stressor, which are responsible for the reactivityenhancing effect we found. Note that social-evaluative threat and low controllability characterize both the TSST and role uncertainty; thus, we combined an acute stressor and a background stressor representing a "match" with regard to these characteristics, and our expectation that such a match would be especially promising (cf. Dickerson \& Kemeny, 2004) was born out. Future studies should try to more systematically test background stressors with various characteristics in order to establish to what extent a match in which kinds of characteristics is necessary to obtain results like ours.

What do our results imply with regard to the role stress model? First, uncertainty as the common element of role ambiguity and role conflict should receive more interest. It has long been noted that role ambiguity and role conflict are not only associated with one another but also tend to show similar associations with other variables (King \& King, 1990). The role of uncertainty in the stress process has been emphasized repeatedly by experts in the field (e.g., Beehr, 1998), not least with regard to its effects on HPA responsivity (Mason, 1975), 
and role uncertainty seems to represent an important part of uncertainty in the work context (cf. Garst et al, 2000; Widmer et al, 2012).

Second, the role stress model should receive more attention in studies on work stress and health. As mentioned in the introduction, there have been some studies relating role ambiguity and/or role conflict to cardiovascular disease or its precursors (cf. Cooper \& Marshall, 1976; Dana \& Griffin, 1999; House, 1974; Howard, Cunningham, \& Rechnitzer, 1986). At the same time, interest in the role stress model seems to have diminished over the years, and recent reviews of stress and illness do not devote much attention to it. One of the consequences of this diminishing interest may be that studies investigating potential effects of work stressors on SAM or HPA stress reactivity have not included role uncertainty as a potential background stressor. To the extent that changes in reactivity to stressors offer a window into the processes involved in "transforming" stress exposure into illness, our results suggest that role uncertainty may play an important role in these processes. We therefore feel that the waning interest in role ambiguity and role conflict is unfortunate, and that future research on occupational stress and (cardiovascular) health should consider role uncertainty to a greater extent. Obviously, the specific contribution of role uncertainty as a background stressor can only be assessed if compared to that of other stressors in addition to those we controlled for. Other uncertainty-related stressors, such as job insecurity, but also additional stressors such as social conflict, might be candidates for such investigations. Our results suggest that such investigations might well be worthwhile.

\section{Strengths and Limitations}

Strengths of our study are that we employed a highly potent standardized stress test, and that we used a background stressor that refers to uncertainty, and therefore should be especially likely to activate the HPA axis, according to the criteria advanced by Mason (Mason, 1968, 1975). Moreover, we used a multimethod approach by combining assessment of subjective self-report data with objective physiological data thus ruling out a 
potential common-method bias. We also controlled for a variety of known and potential confounders to rule out a potential confounding influence on the measured parameters. Finally, since our uncertainty measure refers to more chronic conditions at work and was assessed before we acutely induced physiological stress reactivity, our study design may support the conclusion that it is uncertainty that likely causes heightened physiological stress reactivity rather than vice versa.

Limitations of our study include the cross-sectional nature of our findings, which cannot prove the sequence of events as outlined above, although, as argued above, it seems quite unlikely that heightened cortisol stress reactivity increased role uncertainty. However, the causality of the observed associations and their potential dependence on an unmeasured third variable remain to be tested in prospective analyses. Moreover, our sample size was relatively small and included, due to methodological constraints, only men. Thus, our findings may not be generalizable to women. Furthermore, it is possible that our sample size was insufficient to detect effects of smaller effect size e.g. for blood pressure stress reactivity. Also, we may have missed the blood pressure reactivity peak as we measured blood pressure after but not during stress. Future studies should replicate these findings in larger sample sizes investigating both sexes. In addition, internal consistency for the uncertainty and overcommitment measures are relatively low as compared to larger scale studies (Semmer, et al., 1995; Siegrist, et al., 2004). This might relate to the small sample size, and for role uncertainty also to the fact that this measure is composed of 3 items only; Cronbach's alpha strongly depends on the number of items (Cortina, 1993); from that perspective, a value of just below the conventional .70 does not seem overly disconcerting (Schmitt, 1996).

In sum, although many questions remain, our results underscore the potential occurrence of HPA-dysregulation when faced with chronic exposure to stress at work, and the occurrence of hyper-reactivity when this stress is due to role uncertainty, even at a 
relatively mild intensity. It may well be that the uncertainty induced by this specific type of stressor is an element that is especially likely to trigger rather strong physiological reactions (cf. Beehr's emphasis on uncertainty as an important element in organizational stress, (Beehr, 1998). This issue deserves further attention in future research. Moreover, future studies in occupational settings are needed to determine potential implications of our findings with respect to organizational interventions. For instance, research should evaluate psychobiological health consequences of interventions intended to reduce existing role stress, e.g. by role clarification trainings (Ganster \& Schaubroeck, 1991; Schaubroeck, Ganster, Sime, \& Ditman, 1993).

Acknowledgements: There are no conflicts of interest 


\section{REFERENCES}

Appels, A. (1997). Exhausted subjects, exhausted systems. Acta Physiol Scand Suppl, 640, 153-154.

Appels, A. (2004). Exhaustion and coronary heart disease: the history of a scientific quest. Patient Educ Couns, 55(2), 223-229.

Backe, E. M., Seidler, A., Latza, U., Rossnagel, K., \& Schumann, B. (2012). The role of psychosocial stress at work for the development of cardiovascular diseases: a systematic review. International archives of occupational and environmental health, 85(1), 67-79. doi: 10.1007/s00420-011-0643-6

Beehr, T. A. (1976). Perceived Situational Moderators of Relationship between Subjective Role Ambiguity and Role Strain. Journal of Applied Psychology, 61(1), $35-40$

Beehr, T. A. (1998). An organizational psychology meta-model of occupational stress. In C. Cooper (Ed.), Theories of organizational stress (pp. 6-27). Oxford, UK: Oxford University Press.

Beehr, T.A., \& Bhagat, R.S. (1985). Introduction to human stress and cognition in organizations. In T.A. Beehr \& R.S. Bhagat (Eds.), Human stress and cognition in organizations: An integrated perspective (pp. 3-19). New York: Wiley.

Beehr, T.A., \& Glazer, S. (2005). Organizational Role Stress. In J. Barling, E.K. Kellowag \& M.R. Frone (Eds.), Handbook of Work Stress (pp. 7-33). London: SAGE Publications.

Brotman, D. J., Golden, S. H., \& Wittstein, I. S. (2007). The cardiovascular toll of stress. Lancet, 370(9592), 1089-1100.

Caplan, R. D., \& Jones, K. W. (1975). Effects of Work Load, Role Ambiguity, and Type-a Personality on Anxiety, Depression, and Heart-Rate. Journal of Applied Psychology, $60(6), 713-719$. 
Chida, Y., \& Hamer, M. (2008). Chronic psychosocial factors and acute physiological responses to laboratory-induced stress in healthy populations: a quantitative review of 30 years of investigations. Psychol Bull, 134(6), 829-885.

Chida, Y., \& Steptoe, A. (2010). Greater cardiovascular responses to laboratory mental stress are associated with poor subsequent cardiovascular risk status: a metaanalysis of prospective evidence. Hypertension, 55(4), 1026-1032.

Cooper, C. L., \& Marshall, J. (1976). Occupational Sources of Stress - Review of Literature Relating to Coronary Heart-Disease and Mental Ill Health. Journal of Occupational Psychology, 49(1), 11-28.

Cortina, J. M. (1993). What Is Coefficient Alpha - an Examination of Theory and Applications. Journal of Applied Psychology, 78(1), 98-104. doi: Doi $10.1037 / / 0021-9010.78 .1 .98$

Danna, K., \& Griffin, R. W. (1999). Health and well-being in the workplace: A review and synthesis of the literature. Journal of Management, 25(3), 357-384. doi: Doi 10.1016/S0149-2063(99)00006-9

Dickerson, S. S., \& Kemeny, M. E. (2004). Acute stressors and cortisol responses: a theoretical integration and synthesis of laboratory research. Psychol Bull, 130(3), $355-391$

Dienstbier, R. A. (1989). Arousal and physiological toughness: implications for mental and physical health. [Review]. Psychological review, 96(1), 84-100.

Frone, M. R., Russell, M., \& Cooper, M. L. (1995). Job Stressors, Job Involvement and Employee Health - a Test of Identity Theory. Journal of Occupational and Organizational Psychology, 68, 1-11.

Frost, R.O., Marten, P., Lahart, C.M., \& Rosenblate, P. (1990). The dimensions of perfectionism. Cognitive Therapy and Research, 14, 449-468. 
Gaab, J., Rohleder, N., Nater, U. M., \& Ehlert, U. (2005). Psychological determinants of the cortisol stress response: the role of anticipatory cognitive appraisal. Psychoneuroendocrinology, 30(6), 599-610.

Ganster, D. C., Fusilier, M. R., \& Mayes, B. T. (1986). Role of Social Support in the Experience of Stress at Work. Journal of Applied Psychology, 71(1), 102-110.

Ganster, D. C., \& Schaubroeck, J. (1991). Role Stress and Worker Health - an Extension of the Plasticity Hypothesis of Self-Esteem. Journal of Social Behavior and Personality, 6(7), 349-360.

Garst, H., Frese, M., \& Molenaar, P. C. M. (2000). The temporal factor of change in stressor-strain relationships: A growth curve model on a longitudinal study in East Germany. Journal of Applied Psychology, 85(3), 417-438. doi: Doi $10.1037 / 0021-9010.85 .3 .417$

Geurts, S. A. E., \& Sonnentag, S. (2006). Recovery as an explanatory mechanism in the relation between acute stress reactions and chronic health impairment. Scandinavian Journal of Work Environment \& Health, 32(6), 482-492.

Greenberg, J. (2010). Organizational Injustice as an Occupational Health Risk. Academy of Management Annals, 4, 205-243. doi: Doi 10.1080/19416520.2010.481174

Gump, B. B., \& Matthews, K. A. (1999). Do background stressors influence reactivity to and recovery from acute stressors? Journal of Applied Social Psychology, 29(3), 469-494.

Hamer, M., Endrighi, R., Venuraju, S. M., Lahiri, A., \& Steptoe, A. (2012). Cortisol responses to mental stress and the progression of coronary artery calcification in healthy men and women. [Clinical Trial

Research Support, Non-U.S. Gov't]. Plos One, 7(2), e31356. doi: 10.1371/journal.pone.0031356 
Hamer, M., O'Donnell, K., Lahiri, A., \& Steptoe, A. (2010). Salivary cortisol responses to mental stress are associated with coronary artery calcification in healthy men and women. [Research Support, Non-U.S. Gov't]. European heart journal, 31(4), 424-429. doi: 10.1093/eurheartj/ehp386

Hamer, M., Williams, E., Vuonovirta, R., Giacobazzi, P., Gibson, E. L., \& Steptoe, A. (2006). The effects of effort-reward imbalance on inflammatory and cardiovascular responses to mental stress. [Research Support, Non-U.S. Gov't]. Psychosomatic medicine, 68(3), 408-413. doi: 10.1097/01.psy.0000221227.02975.a0

Hanson, E. K., Schaufeli, W., Vrijkotte, T., Plomp, N. H., \& Godaert, G. L. (2000). The validity and reliability of the Dutch Effort-Reward Imbalance Questionnaire. J Occup Health Psychol, 5(1), 142-155.

House, J. S. (1974). Occupational Stress and Coronary Heart Disease - Review and Theoretical Integration. Journal of Health and Social Behavior, 15(1), 12-27. doi: Doi $10.2307 / 2136922$

Howard, J. H., Cunningham, D. A., \& Rechnitzer, P. A. (1986). Role Ambiguity, Type-a Behavior, and Job-Satisfaction - Moderating Effects on Cardiovascular and Biochemical Responses Associated with Coronary Risk. Journal of Applied Psychology, 71(1), 95-101. doi: Doi 10.1037/0021-9010.71.1.95

Jackson, S.E., \& Schuler, R.S. (1985). A meta-analysis and conceptual critique of research on role ambiguity and role conflict in work settings. Organizational Behavior and Human Decision Processes, 36, 16-78.

Joksimovic, L., Starke, D., v d Knesebeck, O., \& Siegrist, J. (2002). Perceived work stress, overcommitment, and self-reported musculoskeletal pain: a cross-sectional investigation. Int J Behav Med, 9(2), 122-138. 
Kahn, R.L., Wolfe, D., Quinn, A., Snoek, J.D., \& Rosenthal, R. (1964). Organizational Stress: Studies in Role Conflict and Role Ambiguity. New York: Wiley and Sons.

Karasek, R. A. (1979). Job Demands, Job Decision Latitude, and Mental Strain Implications for Job Redesign. Administrative Science Quarterly, 24(2), 285-308. doi: Doi $10.2307 / 2392498$

Karasek, R., \& Theorell, T. (1990). Healthy Work. Stress, Productivity, and the Reconstruction of Working Life. New York: Basic Books.

Kemery, E. R., Bedeian, A. G., Mossholder, K. W., \& Touliatos, J. (1985). Outcomes of Role Stress - a Multisample Constructive Replication. Academy of Management Journal, $28(2), 363-375$

Kemery, E. R., Mossholder, K. W., \& Bedeian, A. G. (1987). Role Stress, Physical Symptomatology, and Turnover Intentions - a Causal-Analysis of 3 Alternative Specifications. Journal of Occupational Behaviour, 8(1), 11-23.

Kirschbaum, C., Pirke, K. M., \& Hellhammer, D. H. (1993). The 'Trier Social Stress Test'--a tool for investigating psychobiological stress responses in a laboratory setting. Neuropsychobiology, 28(1-2), 76-81.

Kivimaki, M., Nyberg, S. T., Batty, G. D., Fransson, E. I., Heikkila, K., Alfredsson, L., ... Theorell, T. (2012). Job strain as a risk factor for coronary heart disease: a collaborative meta-analysis of individual participant data. Lancet. doi: 10.1016/S0140-6736(12)60994-5

Kivimaki, M., Virtanen, M., Elovainio, M., Kouvonen, A., Vaananen, A., \& Vahtera, J. (2006). Work stress in the etiology of coronary heart disease - a meta-analysis. Scandinavian Journal of Work Environment \& Health, 32(6), 431-442.

Kudielka, B. M., Hellhammer, D. H., \& Kirschbaum, C. (2007). Ten years of research with the Trier Social Stress Test (TSST) - revisited. In E. Harmon-Jones \& P. 
Winkielman (Eds.), Social neuroscience: integrating biological and psychological explanations of social behavior (pp. 56-83). New York: The Guilford Press.

Lazarus, R.S., \& Folkman, S. (1984). Stress, appraisal, and coping. New York: Springer Publishing Company.

LePine, J. A., LePine, M. A., \& Saul, J. R. . (2007). Relationships among work and non-work challenge and hindrance stressors and non-work and work criteria: A model of cross-domain stressor effects. In P.L. Perrewé \& D.C. Ganster (Eds.), Exploring the Work and Non-Work Interface (pp. 35-72). Oxford: Elsevier.

LePine, J. A., Podsakoff, N. P., \& LePine, M. A. . (2005). A meta-analytic test of the challenge stressor-hindrance stressor framework: An explanation for inconsistent relationships among stressors and performance. Academy of Management Journal, 48, 764-775.

Linden, W., Gerin, W., \& Davidson, K. (2003). Cardiovascular reactivity: status quo and a research agenda for the new millennium. Psychosom Med, 65(1), 5-8.

Lovallo, W. R., \& Gerin, W. (2003). Psychophysiological reactivity: mechanisms and pathways to cardiovascular disease. Psychosom Med, 65(1), 36-45.

Mason, J. W. (1968). A Review of Psychoendocrine Research on Pituitary-Adrenal Cortical System. Psychosomatic medicine, 30(5P2), 576-\&.

Mason, J. W. (1975). A historical view of the stress field. J Human Stress, 1(1), 6-12 contd. McEwen, B. S. (1998a). Protective and damaging effects of stress mediators. N Engl J Med, $338(3), 171-179$.

McEwen, B. S. (1998b). Stress, adaptation, and disease. Allostasis and allostatic load. Ann N Y Acad Sci, 840, 33-44. 
Melamed, S., Ugarten, U., Shirom, A., Kahana, L., Lerman, Y., \& Froom, P. (1999). Chronic burnout, somatic arousal and elevated salivary cortisol levels. J Psychosom Res, 46(6), 591-598.

O'Driscoll, M. P., \& Beehr, T. A. (1994). Supervisor Behaviors, Role Stressors and Uncertainty as Predictors of Personal Outcomes for Subordinates. Journal of Organizational Behavior, 15(2), 141-155. doi: Doi 10.1002/Job.4030150204

Örtqvist, D., \& Wincent, J. (2006). Prominent consequences of role stress: a meta-analytic review. International Journal of Stress Management, 13(4), 399-422.

Price, R. H., \& Hooijberg, R. (1992). Organizational Exit Pressures and Role Stress Impact on Mental-Health. Journal of Organizational Behavior, 13(7), 641-651.

Pruessner, J. C., Kirschbaum, C., Meinlschmid, G., \& Hellhammer, D. H. (2003). Two formulas for computation of the area under the curve represent measures of total hormone concentration versus time-dependent change. Psychoneuroendocrinology, 28(7), 916-931.

Rizzo, J. R., House, R. J., \& Lirtzman, S. I. (1970). Role Conflict and Ambiguity in Complex Organizations. Administrative Science Quarterly, 15(2), 150-162.

Roedel, A., Siegrist, J., Hessel, A., \& Braehler, E. (2004). Psychometric Test of the Questionnaire Measuring Effort-Reward Imbalance at Work in a Representative German Sample. Zeitschrift für Differentielle und Diagnostische Psychologie, 24(4), 227-238.

Schaubroeck, J., Cotton, J. L., \& Jennings, K. R. (1989). Antecedents and Consequences of Role Stress - a Covariance Structure-Analysis. Journal of Organizational Behavior, $10(1), 35-58$.

Schaubroeck, J., \& Ganster, D. C. (1993). Chronic demands and responsivity to challenge. The Journal of applied psychology, 78(1), 73-85. 
Schaubroeck, J., Ganster, D. C., Sime, W. E., \& Ditman, D. (1993). A Field Experiment Testing Supervisory Role Clarification. Personnel Psychology, 46(1), 1-25.

Schmidt, R.F., \& Thews, G. (1987). Functions of the vascular system (Funktionen des Gefäßsystems). In R.F. Schmidt \& G. Thews (Eds.), Human Physiology (Physiologie des Menschen) (Vol. 21, pp. 518-519). Berlin Heidelberg New York: Springer.

Schmitt, N. (1996). Uses and abuses of coefficient alpha. Psychological Assessment, 8(4), 350-353. doi: Doi 10.1037/1040-3590.8.4.350

Schommer, N. C., Hellhammer, D. H., \& Kirschbaum, C. (2003). Dissociation between reactivity of the hypothalamus-pituitary-adrenal axis and the sympatheticadrenal-medullary system to repeated psychosocial stress. Psychosom Med, 65(3), 450-460.

Seldenrijk, A., Hamer, M., Lahiri, A., Penninx, B. W., \& Steptoe, A. (2012). Psychological distress, cortisol stress response and subclinical coronary calcification. [Research Support, Non-U.S. Gov't]. Psychoneuroendocrinology, 37(1), 48-55. doi: 10.1016/j.psyneuen.2011.05.001

Semmer, N., Zapf, D., \& Dunckel, H. (1995). Assesing stress at work: A framework and an instrument. Work and health: Scientific basis of progress in the working environment, 105-113.

Siegrist, J. (1996). Adverse health effects of high-effort/low-reward conditions. J Occup Health Psychol, 1(1), 27-41.

Siegrist, J., Klein, D., \& Voigt, K. H. (1997). Linking sociological with physiological data: the model of effort-reward imbalance at work. Acta Physiol Scand Suppl, 640, 112116. 
Siegrist, J., Starke, D., Chandola, T., Godin, I., Marmot, M., Niedhammer, I., \& Peter, R. (2004). The measurement of effort-reward imbalance at work: European comparisons. Soc Sci Med, 58(8), 1483-1499.

Sonnentag, S., Binnewies, C., \& Mojza, E. J. . (2010). Staying well and engaged when demands are high: The role of psychological detachment. Journal of Applied Psychology, 95, 965-976.

Spector, P. E., Dwyer, D. J., \& Jex, S. M. (1988). Relation of Job Stressors to Affective, Health, and Performance Outcomes - a Comparison of Multiple Data Sources. Journal of Applied Psychology, 73(1), 11-19.

Steptoe, A., Fieldman, G., Evans, O., \& Perry, L. (1993). Control over work pace, job strain and cardiovascular responses in middle-aged men. Journal of hypertension, 11(7), 751-759.

Steptoe, A., \& Kivimaki, M. (2012). Stress and cardiovascular disease. Nature Reviews Cardiology, 9(6), 360-370. doi: Doi 10.1038/Nrcardio.2012.45

Stöber, J. (1998). The Frost Multidimensional Perfectionism Scale: More perfect with four (instead of six) dimensions. Personality and Individual differences, 24, 481491.

Theorell, T., \& Karasek, R.A. (1996). Current issues relating to psychosocial job strain and cardiovascular disease research. Journal of Occupational Health Psychology, 1, 9-26.

Webster, J. R., Beehr, T. A., \& Love, K. . (2011). Extending the challenge-hindrance model of occupational stress: The role of appraisal. Journal of Vocational Behavior, 79, 505-516.

Widmer, P. S., Semmer, N. K., Kalin, W., Jacobshagen, N., \& Meier, L. (2012). The ambivalence of challenge stressors: Time pressure associated with both negative 
and positive well-being. Journal of Vocational Behavior, 80(2), 422-433. doi: Doi 10.1016/J.Jvb.2011.09.006

Widmer, P. S., Semmer, N. K., Kälin, W., Jacobshagen, N., \& Meier, L. L. . (2012). The ambivalence of challenge stressors: Time pressure associated with both negative and positive well-being. Journal of Vocational Behavior, 80, 422-433. doi: 10.1016/j.jvb.2011.09.006

Wirtz, P. H., Ehlert, U., Emini, L., Rudisuli, K., Groessbauer, S., Gaab, J., . . . von Kanel, R. (2006). Anticipatory cognitive stress appraisal and the acute procoagulant stress response in men. Psychosom Med, 68(6), 851-858.

Wirtz, P. H., Elsenbruch, S., Emini, L., Rudisuli, K., Groessbauer, S., \& Ehlert, U. (2007). Perfectionism and the cortisol response to psychosocial stress in men. Psychosom Med, 69(3), 249-255.

Wirtz, P. H., Kanel, R. V., Emini, L., Suter, T., Fontana, A., \& Ehlert, U. (2007). Variations in anticipatory cognitive stress appraisal and differential proinflammatory cytokine expression in response to acute stress. Brain Behav Immun.

Wirtz, P. H., Redwine, L. S., Ehlert, U., \& von Kanel, R. (2009). Independent association between lower level of social support and higher coagulation activity before and after acute psychosocial stress. Psychosom Med, 71(1), 30-37.

Wirtz, P. H., Siegrist, J., Rimmele, U., \& Ehlert, U. (2008). Higher overcommitment to work is associated with lower norepinephrine secretion before and after acute psychosocial stress in men. Psychoneuroendocrinology, 33(1), 92-99.

Wirtz, P. H., Siegrist, J., Schuhmacher, A., Hoefels, S., Maier, W., \& Zobel, A. W. (2010). Higher overcommitment to work is associated with higher plasma cortisol but not ACTH responses in the combined dexamethasone/CRH test in apparently healthy men and women. Psychoneuroendocrinology, 35(4), 536-543. 
Wirtz, P. H., von Kanel, R., Mohiyeddini, C., Emini, L., Ruedisueli, K., Groessbauer, S., \& Ehlert, U. (2006). Low social support and poor emotional regulation are associated with increased stress hormone reactivity to mental stress in systemic hypertension. J Clin Endocrinol Metab, 91(10), 3857-3865.

Wirtz, P. H., Von Kanel, R., Schnorpfeil, P., Ehlert, U., Frey, K., \& Fischer, J. E. (2003). Reduced Glucocorticoid Sensitivity of Monocyte Interleukin-6 Production in Male Industrial Employees who are Vitally Exhausted. Psychosom Med, 65(4), 672-678. 


\section{Legend to Figure 1}

Values are means \pm SEM. We calculated general linear models with repeated measures of cortisol as dependent variables and role uncertainty as continuous independent variable while controlling for age, BMI, and MAP. Higher uncertainty scores were associated with higher cortisol stress reactivity (interaction group-by-stress: $p=0.016$ ), particularly when additionally controlling for psychological confounders stress appraisal, overcommitment, perfectionism, and time pressure $(p<.001)$. For illustrative purposes we categorized the study subjects into quartiles based on their uncertainty scores with lowest uncertainty in quartile 1 and highest uncertainty in quartile 4 while controlling for the full set of covariates (Figure 1). 
Figure 1. Cortisol reactivity to psychosocial stress (TSST) in subjects with lower and higher scores for role uncertainty at work.

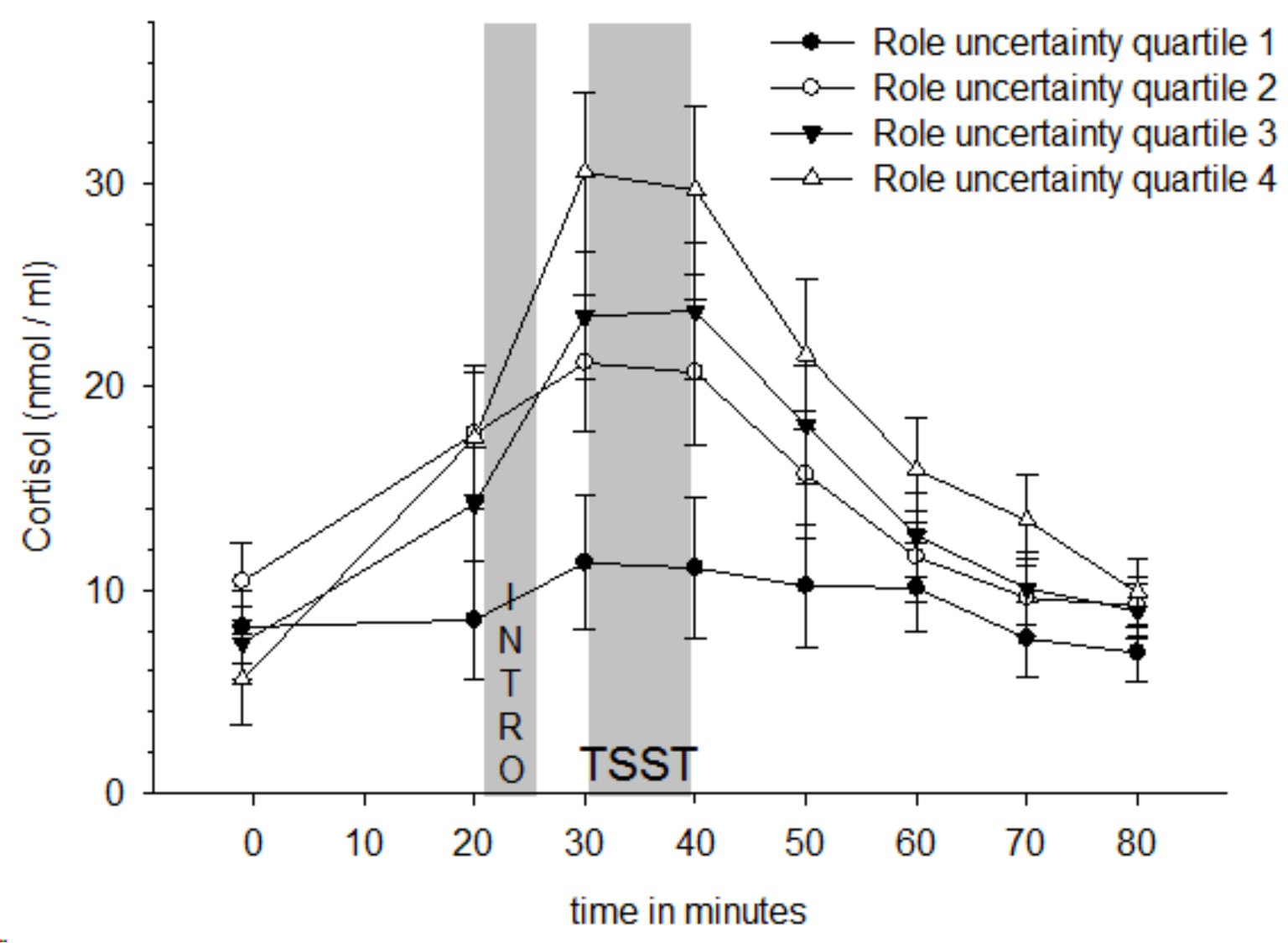


Table 1. Sociodemographic, Medical, and Psychological Characteristics of the Study Subjects

\begin{tabular}{|c|c|c|c|}
\hline & Mean / \% & SEM & Range / N \\
\hline Age [years] & 44.5 & 2.0 & $22-65$ \\
\hline Body mass index $\left[\mathrm{kg} / \mathrm{m}^{2}\right]$ & 25.7 & 0.4 & 20.7-33.9 \\
\hline Mean arterial blood pressure, MAP & 101.1 & 1.8 & $78.5-128.7$ \\
\hline \multicolumn{4}{|l|}{ [mmHg] } \\
\hline High school degree & 51.2 & & 22 \\
\hline \multicolumn{4}{|l|}{ (Swiss "Matura” or } \\
\hline \multicolumn{4}{|l|}{ "Fachhochschulreife") [\% (N)] } \\
\hline Weekly work time [hours] & 46.7 & 2.1 & $16-88$ \\
\hline Role Uncertainty [score] & 1.96 & 0.11 & $1-3.67$ \\
\hline Overcommitment [OC-score] & 17.83 & 3.32 & $12-29$ \\
\hline Perfectionism [CMD score] & 28.60 & 1.23 & $13-51$ \\
\hline Stress appraisal [PASA score] & 2.28 & 0.37 & $-3-6.75$ \\
\hline Time pressure [score] & 2.91 & 0.16 & $1-4.5$ \\
\hline
\end{tabular}

$\mathrm{N}$ : number of observed cases; SEM: standard error of mean 
Table 2. Correlation matrix

\begin{tabular}{|c|c|c|c|c|c|c|c|c|c|c|c|c|c|c|c|c|c|c|c|c|c|c|c|}
\hline $\begin{array}{l}\text { Variabl } \\
\text { es }\end{array}$ & UN & age & BMI & MAP & OC & $\mathrm{TP}$ & Perf & $\begin{array}{l}\text { PAS } \\
\mathrm{A}\end{array}$ & $\begin{array}{l}\text { Cort } \\
1 \\
\end{array}$ & $\begin{array}{l}\text { Cort } \\
2 \\
\end{array}$ & $\begin{array}{l}\text { Cort } \\
3 \\
\end{array}$ & $\begin{array}{l}\text { Cort } \\
4 \\
\end{array}$ & $\begin{array}{l}\text { Cort } \\
5 \\
\end{array}$ & $\begin{array}{l}\text { Cort } \\
6 \\
\end{array}$ & $\begin{array}{l}\text { Cort } \\
7 \\
\end{array}$ & $\begin{array}{l}\text { Cort } \\
8 \\
\end{array}$ & BPS1 & BPS2 & BPS3 & BPS4 & $\begin{array}{l}\text { BPD } \\
1 \\
\end{array}$ & $\begin{array}{l}\text { BPD } \\
2\end{array}$ & BPD3 \\
\hline UN & 1 & & & & & & & & & & & & & & & & & & & & & & \\
\hline Age & $-64^{* *}$ & 1 & & & & & & & & & & & & & & & & & & & & & \\
\hline BMI & $-.33^{*}$ & $.41^{*}$ & 1 & & & & & & & & & & & & & & & & & & & & \\
\hline MAP & -.19 & $.36^{*}$ & $.43^{* *}$ & 1 & & & & & & & & & & & & & & & & & & & \\
\hline $\mathrm{OC}$ & -.13 & $.39 *$ & -.01 & -.10 & 1 & & & & & & & & & & & & & & & & & & \\
\hline $\mathrm{TP}$ & $.43^{* *}$ & -.21 & .06 & .03 & $.34^{*}$ & 1 & & & & & & & & & & & & & & & & & \\
\hline Perf & .23 & .07 & -.19 & -.07 & $.37^{*}$ & -.04 & 1 & & & & & & & & & & & & & & & & \\
\hline PASA & -.22 & $.32 *$ & -08 & -.04 & $.30+$ & .02 & .22 & 1 & & & & & & & & & & & & & & & \\
\hline Cort1 & -.22 & -.05 & -.05 & .07 & -.15 & -.15 & $-.30+$ & .25 & 1 & & & & & & & & & & & & & & \\
\hline Cort2 & .11 & -.04 & .04 & .11 & -.25 & -.27 & -.10 & -.20 & $.37 *$ & 1 & & & & & & & & & & & & & \\
\hline Cort3 & .06 & .20 & $.26+$ & $.26+$ & -.25 & $-.33^{*}$ & .03 & $-.39 *$ & -.05 & $.72^{* *}$ & 1 & & & & & & & & & & & & \\
\hline Cort4 & .04 & $.28+$ & .22 & $.27+$ & -.10 & $-.27+$ & .19 & $-.32^{*}$ & -.10 & $.58^{* *}$ & $.93^{* *}$ & 1 & & & & & & & & & & & \\
\hline Cort5 & -.03 & $.29+$ & $.29+$ & $.30+$ & -.06 & -.26 & .16 & $-.26+$ & .00 & $.58^{* *}$ & $.86^{* *}$ & $.94^{* *}$ & 1 & & & & & & & & & & \\
\hline Cort6 & -.01 & .17 & .26 & .25 & -.16 & -.24 & .13 & $-.31^{*}$ & .02 & $.59^{* *}$ & $.79 * *$ & $.86^{* *}$ & $.91^{* *}$ & 1 & & & & & & & & & \\
\hline Cort7 & -.01 & .16 & .26 & $.30+$ & -.18 & -.24 & .11 & -.22 & .06 & $.68^{* *}$ & $.75^{* *}$ & $.83^{* *}$ & $.89 * *$ & $.95^{* *}$ & 1 & & & & & & & & \\
\hline Cort8 & -.09 & .23 & $.32^{*}$ & $.30+$ & -.13 & $-.26+$ & .09 & -.22 & .13 & $.65^{* *}$ & $.80^{* *}$ & $.86^{* *}$ & $.95^{* *}$ & $.92^{* *}$ & $.92^{* *}$ & 1 & & & & & & & \\
\hline BPS1 & -.16 & $.32 *$ & $.51^{* *}$ & $.90^{* *}$ & -.11 & .11 & -.17 & -.10 & .10 & .06 & $.28+$ & $.27+$ & $.29+$ & .22 & $.330+$ & $.28+$ & 1 & & & & & & \\
\hline BPS2 & -.12 & $.26+$ & $.36^{*}$ & $.75^{* *}$ & -.13 & .10 & -.22 & -.07 & -.01 & .04 & .24 & .24 & .19 & .16 & .19 & .16 & $.70^{* *}$ & 1 & & & & & \\
\hline BPS3 & -.04 & $.35^{*}$ & $.33^{*}$ & $.85^{* *}$ & .02 & .11 & -.08 & .01 & .02 & .14 & $.29+$ & $.30+$ & $.30+$ & .23 & .20 & $.27+$ & $.81^{* *}$ & $.66^{* *}$ & 1 & & & & \\
\hline BPS4 & -.19 & $.30 *$ & .18 & $.83^{* *}$ & -.16 & -.04 & -.02 & -.18 & -.03 & .13 & $.32^{*}$ & $.37^{*}$ & $.37 *$ & $.35^{*}$ & $.33^{*}$ & $.36^{*}$ & $.72^{* *}$ & $.66^{* *}$ & $.75^{* *}$ & 1 & & & \\
\hline BPD1 & -.07 & .18 & .25 & $.84^{* *}$ & -.13 & .07 & -.06 & -.01 & .21 & .14 & .25 & .25 & $.30+$ & .19 & $.28+$ & $.30+$ & $.78^{* *}$ & $.51^{* *}$ & $.68^{* *}$ & $.61^{* *}$ & 1 & & \\
\hline BPD2 & -.02 & $.31 *$ & .18 & $.78^{* *}$ &.-04 & .04 & .10 & .06 & .08 & .11 & $.30+$ & $.33^{*}$ & $.36^{*}$ & $.27+$ & $.30+$ & $.31^{*}$ & $.71^{* *}$ & $.65^{* *}$ & $.68^{* *}$ & $.62^{* *}$ & $.67^{* *}$ & 1 & \\
\hline BPD3 & -.22 & $.36^{*}$ & .25 & $.83^{* *}$ & -.12 & -.10 & .06 & .06 & .14 & .04 & .27 & $.28+$ & $.28+$ & .18 & .18 & .24 & $.70^{* *}$ & $.65^{* *}$ & $.73^{* *}$ & $.71^{* *}$ & $.80^{* *}$ & $.82^{* *}$ & 1 \\
\hline BPD4 & -.21 & $.39 *$ & $.27+$ & $.77^{* *}$ & .02 & .04 & -.03 & .13 & .05 & -.03 & .09 & .16 & .19 & .08 & .11 & .17 & $.65^{* *}$ & $.54^{* *}$ & $.65^{* *}$ & $.51^{* *}$ & $.74^{* *}$ & $.62^{* *}$ & $.75^{* *}$ \\
\hline
\end{tabular}

UN: role uncertainty; BMI: Body Mass Index; MAP: mean arterial blood pressure; OC: overcommitment; TP: time pressure at work; Perf: perfectionism; PASA: Stress appraisal; Cort: cortisol level; BPS: systolic blood pressure; BPD: diastolic blood pressure; ${ }^{* *}$ : significance level $\mathrm{p}<.01$; *: significance level $\mathrm{p}<.05 ;+$ : significance level $\mathrm{p}<.10$. 
Table 3. General linear model results of the interaction between role uncertainty and cortisol stress reactivity over time

$\begin{array}{ccc}\mathrm{F} & \mathrm{Eta} & \mathrm{f} \\ & \text { square } & \end{array}$

Confounder Set 1

Age [years]

3.81

.018

.10

(6.59)

$(<.001)$

Body mass index $\left[\mathrm{kg} / \mathrm{m}^{2}\right]$

.88

.44

.02

Mean arterial blood pressure, .46

.67

.01

MAP [mmHg]

Confounder Set 2

Overcommitment [OC-score]

$(.22)$

(86)

.(01)

Perfectionism [CMD score]

Stress appraisal [PASA score]

$(<.001)$

Time pressure [score]

(2.20)

(.08)

Role Uncertainty [score]

3.94

.016

.10

.33

$(<.001)$

Results without parentheses represent results of the general linear model controlling for confounder set 1 . Results in parentheses represent results of the model controlling for both sets of confounders. 